\title{
Prevalence, antibiogram and risk factors of thermophilic campylobacter spp. in dressed porcine carcass of Chitwan, Nepal
}

Laxman Ghimire ${ }^{{ }^{*}}$, Dinesh Kumar Singh ${ }^{2}$, Hom Bahadur Basnet ${ }^{3}$, Rebanta Kumar Bhattarai ${ }^{3}$, Santosh Dhakal ${ }^{4}$ and Bishwas Sharma ${ }^{5}$

\begin{abstract}
Background: Campylobacter is the primary cause of food borne gastroenteritis. Moreover, the emergence of multiple drug resistant campylobacters from poultry and pork has produced a potential threat to public health. Research addressing these issues is sparse in Nepal. So, this cross-sectional study aims at determining the prevalence, antibiogram and risk factors of campylobacters from dressed porcine carcass of Chitwan, Nepal.

Results: We collected 139 samples of dressed porcine carcass from 10 different pork shops located in Chitwan district and processed according to OIE Terrestrial Manual, 2008, chapter 2.8.10. Antibiogram of identified Campylobacter spp. was evaluated against nine commonly used antibiotics by using disc diffusion method following CLSI guidelines. The prevalence of Campylobacter spp. was 38.84\% (C. coli 76\% and C. jejuni 24\%). There was no significant difference $(p>0.05)$ between the prevalence rate of male $(32.4 \%)$ and female $(41 \%)$ carcass. Ampicillin and erythromycin showed the highest resistance (92.59\% each) followed by colistin (72.2\%), tetracycline (61.1\%), nalidixic acid and cotrimoxazole (44.4\% each), ciprofloxacin (31.5\%) and gentamicin (5.56\%). Moreover, $77.8 \%$ of the isolates were resistant to more than two antimicrobials. Nalidixic acid and tetracycline showed significant difference $(p<0.05)$ in the resistivity pattern among different species of Campylobacters. The association between prevalence rate and regular sanitization of slaughter slab equipments was significant $(p<0.05)$. Similarly, prevalence rate was significantly associated $(p<0.01)$ with chilling and contamination of intestinal content with carcass.
\end{abstract}

Conclusions: The pork meat of Chitwan is highly contaminated with antibiotic-resistant Campylobacters and slaughtering practices play significant role in contamination. It is necessary to train the butchers about hygienic slaughtering practice. The consumers as well as butchers should adopt safety measures to prevent themselves from antibiotic resistant campylobacters. The veterinary practitioners should adopt prudent use of antibiotics in pigs.

Keywords: Campylobacter, Prevalence, Antibiotic resistance, Risk factors, Nepal

\section{Background}

Campylobacter is the leading cause of bacterial zoonotic gastroenteritis in both developing and developed countries [1]. It causes 2 to 7 times more diarrheal cases than Salmonella, Shigella or E. coli O157:H7 [2]. C. jejuni is primarily responsible for human campylobacteriosis. However, the role of C. coli cannot be neglected because

\footnotetext{
* Correspondence: ghimire.laxman13@gmail.com

${ }^{1}$ Institute of Agriculture and Animal Science, Rampur Campus, Nepal; and

Manager at Dairy Value Chain-Development Project, Dang, Nepal

Full list of author information is available at the end of the article
}

many studies from Spain and United Kingdom have emphasized the importance of $C$. coli because of its multiple antibiotic resistance property and its ability to cause acquired food borne enteric infections [3,4]. C. coli contribute about $9 \%$ of human campylobacteriosis in USA [5] and about 7\% in England and Wales [6]. C. coli cases are even higher than $C$. jejuni in older people [6,7] and in summer [7]. Pork is considered to be the major reservoir of C. coli [8]. Various studies have reported C. coli as a potential source of human campylobacteriosis. In the United Kingdom, Gillespie et al., showed that individuals
Ciomed Central 
harboring $C$. coli infection were more likely to have eaten pork pate than those infected with $C$. jejuni [6]. Similarly, in a large case control study in the USA, Friedman et al., 2004 showed the consumption of hamburgers, pork roasts and sausages as an important risk factor for Campylobacter infection [9]. Most of the researches are concentrated on C. jejuni and less is explored about C. coli [4]. Therefore, this paper focus on prevalence, antibiogram and risk factors associated with $C$. coli in porcine carcass.

Most of the cases of Campylobacter infection are self limiting and do not require medication. However, an acute post-infectious ascending paralysis may occur (GuillainBarr'e syndrome) that is considered most common cause of flaccid paralysis after polio [1]. This condition and severe prolonged infection require treatment. Macrolids and fluroquinolones are drugs of choice for treatment of human campylobacteriosis [10]. However, resistance to these groups of antibiotics have been reported from different part of the world [11,12]. Resistance to fluroquinolones in the treatment of severe cases of human campylobacteriosis has risen in USA since 1990 [13].

Very few studies have been done in Nepal regarding campylobacteriosis. A cohort study was carried out on 77 expatriate adults who had lived in Nepal for $<2$ years by Shlim et al., 1999 to find out the cause of travelers' diarrhoea among foreigners in Nepal [14]. Among the causative agents, Campylobacter was one of them. He found the annual attack rate of campylobacter as $10 \%$. There are no other available records of human Campylobacteriosis in Nepal. This is probably because most of the cases of Campylobacters go undiagnosed because these cases do not require hospitalization. Moreover, the isolation of Campylobacter need sophisticated laboratory and is often time and labor consuming. The consumption rate of pork is increasing in Nepal and at the same time the butchers and consumers are unaware about this issue. In a study carried out by Ghimire et.al., 2013, the condition of pig slaughter slabs was miserable and butchers were unaware about campylobacteriosis [15]. There was high chance of cross-contamination of carcass during slaughtering procedure. So, Nepalese might be at high risk and it is essential to estimate the prevalence of Campylobacters in pork. Antibiotics are widely used in pigs of Nepal for therapeutic and prophylactic purpose [16]. Nepalese people may be constantly consuming antibiotic resistant Campylobacters through pork meat. So, this study is done to determine prevalence, antibiogram and risk factors of Campylobacter spp. in dressed porcine carcass of Chitwan district.

\section{Methods}

This cross-sectional study was conducted from September 2012 to January 2013.

\section{Questionnaire and survey}

A set of semi-structured comprehensive questionnaire was developed focusing on i) condition of water, ii) sanitization of equipments, iii) slaughterhouse practices and condition, and iv) contamination of carcass with intestinal content. All of the slaughter slabs and retail pork meat shops in Chitwan were visited and butchers were interviewed.

\section{Sample collection}

There are 5 slaughter slabs and 5 retail pork meat shops in Chitwan district. Altogether 139 pooled samples of pork meat (each sample contain meat from neck, ham, shoulder and skin) were collected aseptically from all of these slaughter slabs and retail pork shops in UV sterilized plastic zipped bags and transported immediately to Veterinary Microbiology Laboratory of the IAAS, Rampur in ice cooled box for further processing.

\section{Bacterial culture}

Isolation and identification of thermophilic Campylobacter spp. was done according to OIE Terrestrial Manual 2008, chapter 2.8.10. The collected samples were immediately processed without storage. About $10 \mathrm{gm}$ of each samples were mixed with $90 \mathrm{ml} 0.1 \%$ buffered peptone water (pH 7.2) (M614, HiMedia lab, Mumbai, India) and homogenized manually for pre-enrichment. One volume of homogenized fluid was added to nine volume of Bolton broth (CM0983, Oxoid ltd, Basingstoke, Hampshire, England) for enrichment and then subjected to incubation in microaerophilic atmosphere obtained by burning candle in candle jar (BD1777SE, Don Whitely Scientific Ltd, England) at $37^{\circ} \mathrm{C}$ for 5 hours and then at $42^{\circ} \mathrm{C}$ for next 43 hours.

Following incubation, one loopful of broth culture was streaked on modified CCDA (mCCDA) and incubated at $42^{\circ} \mathrm{C}$ in a microaerophilic atmosphere for $48 \mathrm{hrs}$ in candle jar. When suspected colonies were detected, confirmatory tests including Gram,s stain, growth at $25^{\circ} \mathrm{C}$, oxidase and catalase tests, sensitivity to nalidixic acid and cephalothin and hippurate hydrolysis were performed.

\section{Antibiogram of the isolated species}

Antibiogram of identified Campylobacter spp. was evaluated against nine different antibiotics (ampicillin, chloramphenicol, ciprofloxacin, nalidixic acid, erythromycin, tetracycline, gentamicin, colistin, and cotrimoxazole) by disc diffusion method following CLSI guidelines. Platinum loop was used to pick pure Campylobacter spp. colonies from the mCCDA plates and turbid suspension was made by emulsifying colonial growth in BHI broth. The turbidity of the inoculums was adjusted to the equivalent turbidity of 0.5 McFarland standards and the broth was incubated 
in microphilic condition for 48 hours in anaerobic jar with lighting candle.

After incubation, $100 \mu \mathrm{l}$ of Brain Heart Infusion broth (M210, HiMedia lab, Mumbai, India) was dispersed over the surface of a Mueller Hinton Agar (MHA) (M173, HiMedia lab, Mumbai, India) with 5\% defibrinated sheep blood to produce a lawn of confluent of bacteria on the surface of agar. Using sterile tweezers, antimicrobial discs were placed widely spaced aseptically on the surface of MHA plate. Tweezers were reflamed after application of each disc. The plates were then incubated in microaerophilic condition at $37^{\circ} \mathrm{C}$ for 24 hours.

Following incubation, the diameter of zone of inhibition was recorded to nearest millimeters for each discs used and then classified as sensitive, intermediate and resistant based on the criteria of Huysmans and Turnidge, 1997 for ampicillin, chloramphenicol, ciprofloxacin, erythromycin, nalidixic acid and tetracycline and for other antimicrobial disc used, CLSI guideline for Enterobacteriaceae was followed. Multiple antibiotic resistance (MAR) was calculated by dividing the total number of antibiotics used by number of antibiotics resistant to particular isolates [17]. In this study, 9 antibiotics were used and are represented as (b), while number of antibiotics resistant to particular isolate is as e.g. 4 (a). MAR is calculated as $\mathrm{a} / \mathrm{b}$, which means that in this particular case, MAR is $4 / 9=0.44$.

\section{Statistical analysis}

Data entry, management and analysis was done using program Microsoft Office Excel 2007. The association between different risk factors and the antibiotics resistivity pattern of isolated Campylobacters were compared statistically by a Chi-square ( $\mathrm{X}$ [2]) analysis using commercial software PHStat2 version 2.5 and Fisher exact test with significance level defined at the $\mathrm{p}<0.05$. The diameter of zone of inhibition of different antibiotics was compared by using $t$-Test: Two samples assuming equal variances.

\section{Results}

The prevalence rate was found to be $38.85 \%$ (54/139). Among the isolates, 42 (77.8\%) were Campylobacter coli and $12(22.2 \%)$ were Campylobacter jejuni. The prevalence rate in male and female carcass is $32.4 \%(11 / 34)$ and $41 \%(43 / 105)$ respectively. The sex-wise prevalence was statistically non-significant $(\mathrm{p}>0.05)$.

The antimicrobial sensitivity pattern of $C$. coli and $C$. jejuni is shown in Figures 1 and 2 respectively. The Campylobacter spp. showed significant $(\mathrm{p}<0.05)$ difference in resistivity pattern with tetracycline and nalidixic acid however, both the species showed similar resistivity pattern with other antimicrobials (Figure 3).

The mean disc diffusion zone among C. coli and C. jejuni were significantly different $(\mathrm{p}<0.01)$ for chloramphenicol and gentamicin and non significant $(\mathrm{p}>0.05)$ for ciprofloxacin, erythromycin, ampicillin, nalidixic acid, cotrimoxazole, tetracycline and colistin (Table 1).

MAR index of the isolated Campylobacter spp. are shown in Table 2. Every isolates were resistant to at least one of the antimicrobials used in this study. Moreover, $92.6 \%$ of the total isolates were resistant to more than one and $77.8 \%$ of the isolates were resistant to more than two antibiotics. C. coli (85.7\%) showed greater multiple antibiotic (more than two) resistance as compared to $C$. jejuni (50\%). $22 \%$ of the isolates had MAR index between 0.1 and 0.2 and $77.8 \%$ of the isolates have MAR index greater than 0.2. The most common multiple antibiotic resistant pattern was ery-amp (85\%).

Different factors that influence the prevalence of Campylobacters in pork is shown in Table 3. The prevalence rate

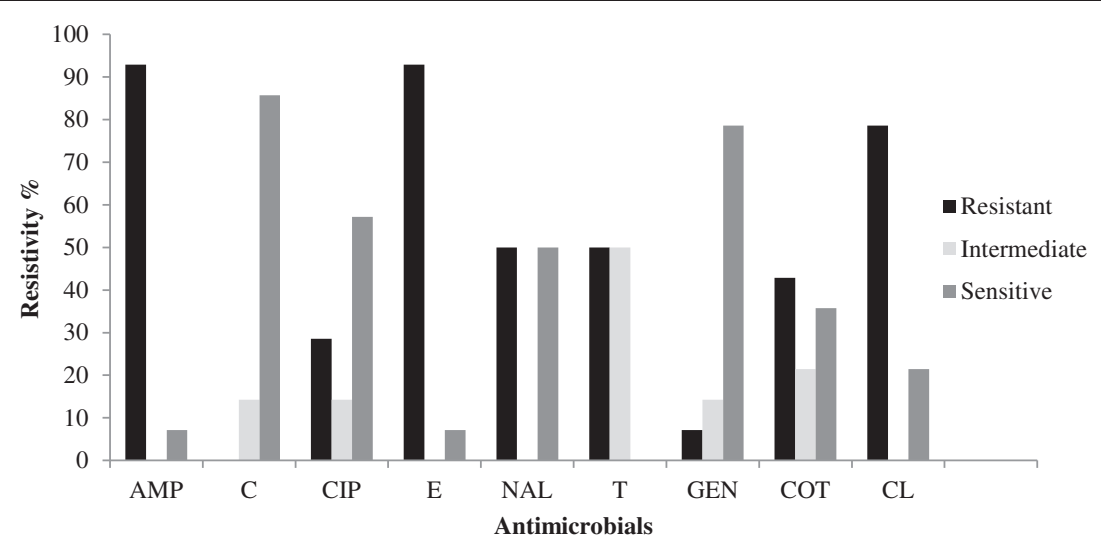

AMP=ampicillin, $\quad \mathrm{C}=$ chloramphenicol, $\quad \mathrm{CIP}=$ ciprofloxacin, $\quad \mathrm{E}=$ erythromycin,

$\mathrm{NAL}=$ nalidixic acid, $\mathrm{T}=$ tetracycline, $\mathrm{GEN}=$ gentamicin, $\mathrm{COT}=$ cotrimoxazole, $\mathrm{CL}=$ colistin

Figure 1 Antimicrobial sensitivity pattern of $C$. coli from dressed porcine carcass. 


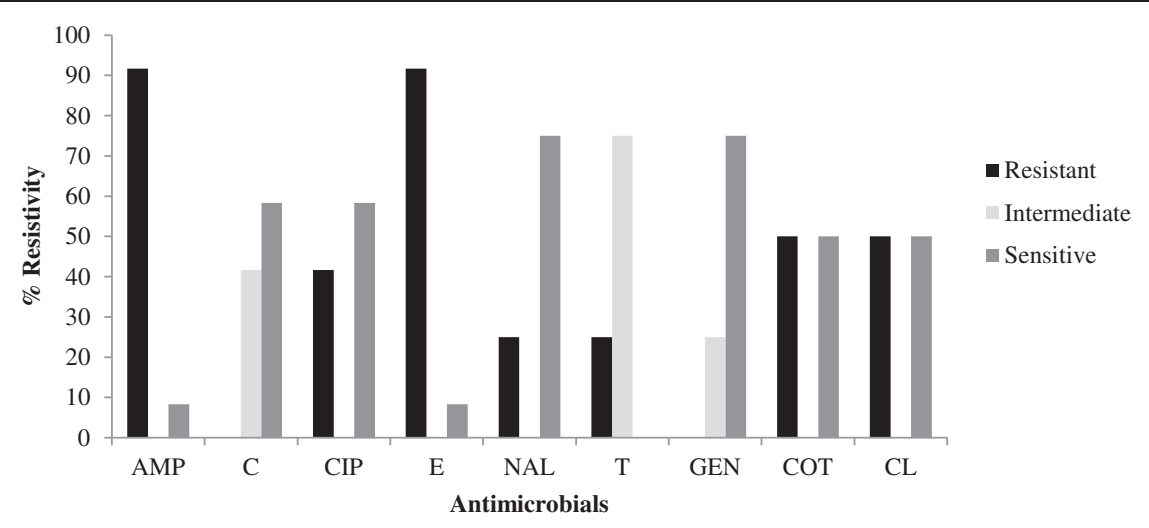

$\mathrm{AMP}=$ ampicillin, $\mathrm{C}=$ chloramphenicol, $\mathrm{CIP}=$ ciprofloxacin, $\mathrm{E}=$ erythromycin, $\mathrm{NAL}=$ nalidixic

acid, $\mathrm{T}=$ tetracycline, GEN=gentamicin, $\mathrm{COT}=$ cotrimoxazole, $\mathrm{CL}=$ colistin

Figure 2 Antimicrobial sensitivity pattern of $C$. jejuni from dressed porcine carcass.

was significantly associated with frequency of sanitization of equipments $(\mathrm{p}<0.05)$, contamination of carcass with intestinal content $(\mathrm{p}<0.01)$ and chilling $(\mathrm{p}<0.01)$ (Table 3$)$.

\section{Discussion}

Campylobacters are regarded as important food borne pathogens. In this study, we found the prevalence of Campylobacter spp. in pork meat of $38.85 \%$. This is higher than that previously found in New Zealand (9.1\%) [19] and Italy (10.3\%) [20], similar to that reported in one 2003 US study (33\%) [18], but lower than more recent US study of dressed rib meat (49\%) [22] at US. It is also significantly lower than the prevalence rate of $67 \%$ found in slaughtered pigs in Tanzania [21].

These differences may be due to slaughtering practices, antibiotic usage, or intrinsic carriage rates. Some of the differences in prevalence rates may also reflect differences in methods used to culture the Campylobacter.

This study has also shown higher prevalence rate of $C$. coli than that of $C$. jejuni in pork which is supported by many other research like von Alrock et al. in 2012 (C. coli 76\% and C. jejuni 24\%) [23] and Jonker in 2009 (C. coli $83.3 \%$ and C. jejuni $17.7 \%$ ) [24].

Several studies have shown the occurrence of antimicrobial resistance among Campylobacter isolates [25-28]. Most of the isolates in this study (>90\%) showed resistance towards ampicillin and erythromycin. This finding is similar to the findings of other investigators in Spain (81.1\%) [3] and Denmark (74.4\%) [29]. In a study carried out in 2011 in South Africa, Uaboi-Egbenni et al. reported $100 \%$ resistance in one farm and $50 \%$ resistance in another farm for C. jejuni from pig towards

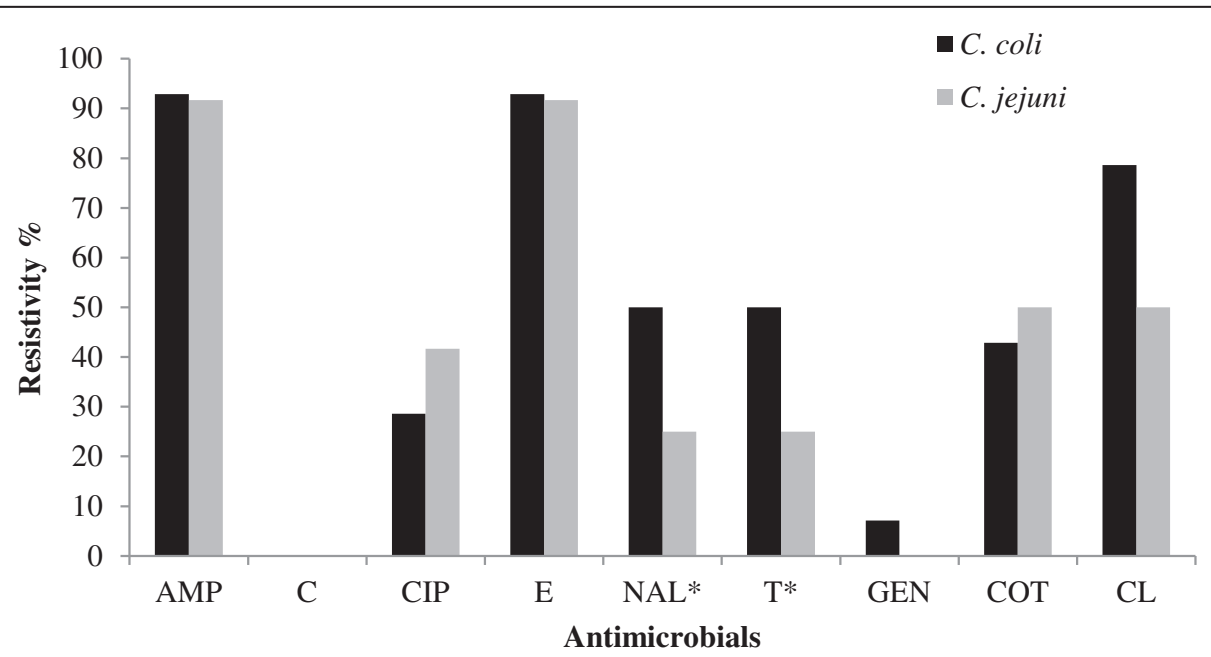

Figure 3 Antimicrobial resistance pattern of $C$. coli and C. jejuni. 
Table 1 Mean disc diffusion zone diameter for Campylobacter spp.

\begin{tabular}{lccc}
\hline Antimicrobials & $\begin{array}{c}\text { C. coli } \\
\text { Mean } \pm \text { SE }(\mathbf{m m})\end{array}$ & $\begin{array}{c}\text { C. jejuni } \\
\text { Mean } \pm \text { SE }(\mathbf{m m})\end{array}$ & p-value \\
\hline Ampicillin & $9.36 \pm 0.201$ & $9.17 \pm 0.167$ & $p>0.05$ \\
Chloramphenicol & $25.50 \pm 0.464$ & $21.75 \pm 1.232$ & $p<0.01$ \\
Ciprofloxacin & $21.43 \pm 1.037$ & $20.75 \pm 2.125$ & $p>0.05$ \\
Erythromycin & $11.14 \pm 0.417$ & $10.42 \pm 0.417$ & $p>0.05$ \\
Nalidixic acid & $15.57 \pm 0.996$ & $14.75 \pm 0.863$ & $p>0.05$ \\
Tetracycline & $18.36 \pm 1.078$ & $19.25 \pm 1.887$ & $p>0.05$ \\
Gentamicin & $16.64 \pm 0.467$ & $20.50 \pm 1.422$ & $p<0.01$ \\
Cotrimoxazole & $15.86 \pm 1.167$ & $15.00 \pm 1.508$ & $p>0.05$ \\
Colistin & $10.79 \pm 0.265$ & $11.00 \pm 0.302$ & $p>0.05$ \\
\hline
\end{tabular}

erythromycin [12]. In the same study, he reported the resistivity of $100 \%$ for C. coli in one farm and $64 \%$ resistance in another farm towards ampicillin.

Tetracycline showed significant difference in the resistivity pattern between $C$. coli and $C$. jejuni. This finding is in agreement with the findings of Mattheus et al. in 2012 [31]. The resistivity pattern of C. coli in this study is in line with Sato et al. and Thakur et al. in 2004 and 2005 respectively $[32,33]$. Some researchers have shown higher resistivity of tetracycline [3,31]. Nalidixic acid showed significant difference in the resistivity pattern between C. coli and C. jejuni (C. coli being 50\% and C. jejuni being 25\%). Similar to this finding, Mattheus et al. reported the resistivity upto $48.8 \%$ in $C$. coli from pigs of Belgium however, he showed decreasing trend of resistivity since 2005 [31].

C. jejuni showed higher resistivity (41.7\%) than C. coli (28.6\%) for ciprofloxacin with $31.5 \%$ overall resistivity. The result of this study is in line with Gallay et al. in pigs of France [25]. Similarly, Uaboi-Egbenni et al. observed

Table 2 Multiple antibiotic resistance (MAR) indices of C. coli and C. jejuni

\begin{tabular}{lll}
\hline $\begin{array}{l}\text { MAR } \\
\text { index }\end{array}$ & \multicolumn{2}{l}{ Percentage frequency of MAR index (\%) } \\
\cline { 2 - 3 } C. coli & C. jejuni \\
\hline 0 & 0 & 0 \\
0.1 & 7.1 & 8.3 \\
0.2 & 7.1 & 41.7 \\
0.3 & 21.4 & 0 \\
0.4 & 7.1 & 8.3 \\
0.5 & 0 & 0 \\
0.6 & 28.6 & 0 \\
0.7 & 21.4 & 41.7 \\
0.8 & 7.1 & 0 \\
0.9 & 0 & 0 \\
1 & 0 & 0 \\
\hline
\end{tabular}

Table 3 Factors influencing prevalence of Campylobacter spp.

\begin{tabular}{|c|c|c|c|}
\hline Risk factors & $\%$ of samples examined & Prevalence rate & p-value \\
\hline \multicolumn{4}{|l|}{ Sex } \\
\hline Male & $24.46(34 / 139)$ & $32.35(11 / 34)$ & $p>0.05$ \\
\hline Female & $75.54(105 / 139)$ & $41(43 / 105)$ & \\
\hline \multicolumn{4}{|c|}{ Sanitation of equipments } \\
\hline \multicolumn{4}{|c|}{ Cleaning of Achano* } \\
\hline Daily & $59.7(83 / 139)$ & $30.1(25 / 83)$ & $p<0.05$ \\
\hline Not daily & $40.3(56 / 139)$ & $51.8(29 / 56)$ & \\
\hline \multicolumn{4}{|c|}{ Cleaning of weighing machine* } \\
\hline Daily & $30.2(42 / 139)$ & $26.1(11 / 42)$ & $p<0.05$ \\
\hline Not daily & $69.8(97 / 139)$ & $44.33(43 / 97)$ & \\
\hline \multicolumn{4}{|c|}{ Contamination of carcass with intestinal content ${ }^{* *}$} \\
\hline Sometimes & $65(65 / 100)$ & $64.6(42 / 65)$ & $p<0.01$ \\
\hline Never & $35(35 / 100)$ & $34.3(12 / 35)$ & \\
\hline \multicolumn{4}{|l|}{ Chilling** } \\
\hline Yes & $19.4(27 / 139)$ & $3.7(1 / 27)$ & $p<0.01$ \\
\hline No & $80.6(112 / 139)$ & $47.3(53 / 112)$ & \\
\hline
\end{tabular}

In the above table, *indicates significant at $\mathrm{p}<0.05$ and $*$ *indicates highly significant $(p<0.01)$.

$40 \%$ resistance in one of the pig farm in South Africa in 2011 [12] and Mattheus et al. reported the trend of ciprofloxacin resistance in the range of $20 \%$ and $48.8 \%$ from 2004 to 2009 in Belgium [31]. The overall resistivity is in close association with the reporting of Mattheus et al. in 2012 from pork meat of Belgium [31]. However, higher resistivity has been reported from other parts of Europe ( 28 to $100 \%)[3,20]$. Fluroquinolones are the drug of choice after erythromycin for the treatment of Campylobacteriosis in human. Therefore, emergence of fluroquinolone resistance is a serious matter of concern and potential threat to public health.

Gentamicin resistance was found low (7.1\% in C. coli and $0 \%$ in $C$. jejuni with $5.5 \%$ overall resistivity) in comparison to other antimicrobials used in this study. In a research performed in 2007 in Canada, Norma et al. found $0.2 \%$ resistivity against gentamicin [34]. This research has regarded gentamicin and chloramphenicol as safe and effective drugs for the treatment of human campylobacteriosis if pork is considered as the source of infection. However, in-vitro antibiotic sensitivity test should be carried for severe or prolonged or immune compromised cases of food borne campylobacteriosis if the source is unknown.

The prevalence of Campylobacters in chilled and unchilled carcass was statistically significant $(\mathrm{p}<0.01)$. In a study in 1985, Oosterom et al. isolated Campylobacter spp. from $9 \%$ and $0 \%$ of the carcasses before and after chilling, respectively [35]. Similarly, in 2008, Nesbakken et al. reported $56.7 \%$ and $1.7 \%$ prevalence before and after 
blast freezing of the carcass [36]. Similarly, in 2003, Pearce et al. detected the prevalence rate of $33 \%$ in carcass prior to chilling and $0 \%$ in chilled carcass [18]. So, lack of chilling the carcass is identified as a risk factor for prevalence of campylobacters in dressed pork.

The prevalence rate in slaughter slab where contamination of carcass with intestinal content occurs sometimes was significantly higher compared to the slaughter slab where such contamination never occurred $(\mathrm{p}<0.01)$. This is due to the fact that the intestinal content of pig is highly contaminated with Campylobacter $[8,19,30]$. So, contamination of carcass with intestinal content is another risk factor for prevalence of campylobacters in pork.

The prevalence of Campylobacter spp. from slaughter slabs and retail shops where wooden chopping board (Achano) was not cleaned daily was significantly higher $(\mathrm{p}<0.05)$ compared to those cleaning the chopping wood (Achano) daily. This shows that chopping wood used in slaughter slab could be potential source of Campylobacter contamination but samples from these equipments were not cultured for confirmation. So, further research is needed for confirmation. Similarly significant difference $(\mathrm{p}<0.05)$ in the prevalence of Campylobacter spp. was observed between the pork meat shop that regularly cleaned the weighing machine and others that do not clean weighing machine regularly. So, slaughtering equipments are also risk factors for campylobacter contamination in pork. Oosterom et al. in 1985, ICMSF in 1998 and Pearce et al. in 2003 have also regarded slaughtering equipments as important risk factors for cross contamination of campylobacter in pork $[18,35,37]$.

The MAR index for the isolated campylobacters is very high in this research which is suggestive of public health hazard. All of the isolates are resistant to at least one of the most of commonly used antibiotics included in this study. More importantly, $28.6 \%$ of the isolated C. coli were resistant to six different antibiotics and $21.4 \%$ were resistant to seven different antibiotics used in the study. This implies severe threat to public health. Likewise, $41.7 \%$ of the isolated C. jejuni were resistant to seven different antibiotics used in the study. The reason behind this may be due to excessive use of antibiotics in pig for treatment as well as growth promoter. The other reason may be due to environmental crosscontamination through other risk factors such as contact with reservoirs like human. This shows that Nepalese people are constantly consuming multiple antibiotic resistant campylobacters in their diet through pork meat. Ery-Amp was the most common resistant pattern (85\%) regardless of the species whereas, Thakur and Gebreyes reported ery-tet as most common resistant pattern $(60.6 \%)$ in porcine carcass from conventional pig rising farms in 2005 [33].

\section{Conclusions}

The pork meat of Chitwan district is highly contaminated with multiple antibiotic resistant thermophilic Campylobacter spp. in which $C$. coli followed by $C$. jejuni are predominant species. Both the butchers and consumers should be made aware regarding this issue. The isolated Campylobacters showed highest resistivity to macrolids, ampicillin and fluoroquinolones and highest sensitivity to chloramphenicol and gentamicin. So, chloramphenicol and gentamicin should be preferred for the treatment of campylobacteriosis in pigs as well as in human if it is suspected of pig origin. Veterinarians and para-veterinarians should adopt prudent use of antibiotics in pigs. Contamination of intestinal content during slaughtering, cross contamination through slaughter house equipments and lack of chilling facilities are the major risk factors of Campylobacter contamination. Routine monitoring of slaughter slab condition and strict implementation of Animal Slaughter and Meat Inspection Act 2055 should be done together with the awareness campaign for the butchers and consumers.

\section{Competing interests}

None of the authors have any competing interests.

\section{Authors' contributions}

LG participated in study design, bacterial culture, data analysis and drafting manuscript, DKS participated in data analysis and bacterial culture identification, HBB participated in bacterial culture and identification, antibiogram and drafting manuscript, RKB conducted bacterial culture, antibiogram and assisted in drafting manuscript, SD participated in data analysis and interpretation, survey of butchers and manuscript preparation and BS participated in bacterial culture, survey of butchers and drafting manuscript. All the authors read and approved the final manuscript.

\section{Acknowledgement}

We are immensely grateful to the butchers who co-operated us during the research period. Our greatest gratitude to microbiology laboratory staffs of Veterinary Teaching Hospital, Tribhuvan University, for their cooperation.

\section{Author details}

${ }^{1}$ Institute of Agriculture and Animal Science, Rampur Campus, Nepal; and Manager at Dairy Value Chain-Development Project, Dang, Nepal. ${ }^{2}$ Department of Pathology and Clinics (HOD), Tribhuvan University, Institute of Agriculture and Animal Science, Rampur Campus, Chitwan, Nepal. ${ }^{3}$ Department of Microbiology and Parasitology (HOD), Tribhuvan University, Institute of Agriculture and Animal Science, Rampur Campus, Chitwan, Nepal. ${ }^{4}$ The Ohio State University, Columbus, USA. ${ }^{5}$ Department of Microbiology and Biochemistry, Himalayan College of Agricultural Sciences and Technology, Kathmandu, Nepal.

Received: 13 September 2013 Accepted: 31 March 2014 Published: 5 April 2014

\section{References}

1. WHO/CDS/CSR/APH: The Increasing Incidence of Human Campylobacteriosis, Report and Proceedings of a WHO Consultation of Experts. Copenhagen, Denmark: World Health Organization; 2000. http://whqlibdoc.who.int/hq/ 2001/who_cds_csr_aph_2001.7.pdf.

2. Blaser MJ, Wells JG, Feldman RA, Pollard RA, Allen JR: Campylobacter enteritis in the United States: a multicenter study. Ann Intern Med 1983, 98:360-365.

3. Saenz $Y$, Zarazaga M, Lantero M, Gastanares MJ, Baquero F, Torres C: Antibiotic resistance in Campylobacter strains isolated from animals, foods, and humans in Spain in 1997-1998. Antimicrob Agents Chemother 2000, 44:267-271. 
4. Tam CC, O'Brien SJ, Adak GK, Meakins SM, Frost JA: Campylobacter coli-an important foodborne pathogen. J Infect 2003, 47:28-32.

5. CDC: National Antimicrobial Resistance System, Enteric Bacteria, Human Isolates Final Report 2010. CDC, Atlanta, Georgia: U.S. Department of Health and Human Services; 2012:1-74. Available: www.cdc.gov/narms/pdf/2010annual-report-narms.pdf

6. Gillespie IA, O'Brien SJ, Frost JA, Adak GK, Horby P, Swan AV, Painter MJ, Neal KR, Collaborators TCSSS: A case-case comparison of Campylobacter coli and Campylobacter jejuni infection: A tool for generating hypotheses. Emerg Infect Dis 2002, 8:937-942.

7. Roux F, Sproston E, Rotariu O, MacRae M, Sheppard SK, Bessell P, Smith-Palmer A, Cowden J, Maiden MCJ, Forbes KJ, Strachan NJC: Elucidating the Aetiology of human Campylobacter coli infections. PLoS One 2013, 8(5):e64504.

8. Young CR, Harvey R, Anderson R, Nisbet D, Stanker LH: Enteric colonization following natural exposure to Campylobacter in pigs. Res Vet Sci 2000, 68:75-78.

9. Friedman CR, Hoekstra RM, Samuel M, Marcus R, Bender J, Shiferaw B, Reddy S, Ahuja SD, Helfrick DL, Hardnett F, Carter M, Anderson B, Tauxe RV, Emerging Infections Program FoodNet Working Group: Risk factors for sporadic Campylobacter infection in the united states: a case-control study in FoodNet sites. Clin Infect Dis 2004, 38(Suppl 3S):285-296.

10. Engberg J, Aarestrup MF, Taylor DE, Gerner-Smidt P, Nachamkins I: Quinolone and macrolide resistance in campylobacter jejuni and C. Coli: resistance mechanisms and trends in human isolates. Emerg Infect Dis 2001, 7(1):24-34

11. Nachamkin I, Ung H, Li M: Increasing fluoroquinolone resistance in Campylobacter jejuni, Pennsylvania, USA, 1982-2001. Emerg Infect Dis 2002, 8:1501-1503.

12. Uaboi-Egbenni PO, Bessong PO, Samie A, Obi C: Prevalence, haemolysis and antibiogram of Campylobacters isolated from pigs from three farm settlements in Venda region, Limpopo province, South Africa. Afri 」 Biotechnol 2011, 7(4):703-711

13. Gupta A, Nelson JM, Barrett TJ, Tauxe RV, Rossiter SP, Friedman CR, Joyce KW, Smith KE, Jones TF, Hawkins MA, Shiferaw B, Beebe JL, Vugia DJ, Rabatsky-Ehr T, Benson JA, Root TP, Angulo FJ, NARMS Working Group: Antimicrobial resistance among Campylobacter strains, United States, 1997-2001. Emerg Infect Dis 2004, 10:1102-1109.

14. Shlim DR, Hoge CE, Rajah R, Scott RM, Pandy P, Echeverria P: Persistent high risk of diarrhea among foreigners in Nepal during the first 2 years of residence. Clin Infect Dis 1999, 29(3):613-616.

15. Ghimire L, Dhakal S, Pandeya YR, Chaulagain S, Mahato BR, Satyal RC: Assessment of pork handlers' knowledge and hygienic status of pig meat shops of Chitwan district focusing campylobacteriosis risk factors. Int J Infect Microbial 2013, 2:17-21.

5. WHO/CDS/CSR/DRS: Antibiotic Resistance: Synthesis of Recommendation by Expert Policy. World Health Organisation; 2001. http://www.who.int/ drugresistance/Antimicrobial_resistance_recommendations_of_expert_polic.pdf.

17. Riaz S: Antibiotic susceptibility pattern and multiple antibiotic resistances (MAR) calculation of extended spectrum $\beta$-lactamase (ESBL) producing Escherichia coli and Klebsiella species in Pakistan. Afr J Biotechnol 2011, 10(33):6325-6331.

18. Pearce RA, Wallace FM, Call JE, Dudley RL, Oser A, Yoder L, Sheridan Jر Luchansky JB: Prevalence of Campylobacter within a swine slaughter and processing facility. J Food Prot 2003, 66:1550-1556.

19. ESR (Institute of Environmental Science \& Research Limited): Risk profile: Campylobacter jejuni/coli in red meat. 2007. Prepared as a part of a New Zealand Food Safety Authority contract for scientific services. http://www. foodsafety.govt.nz/elibrary/industry/Risk_Profile_Campylobacter_Jejuni_ColiScience_Research.pdf.

20. Pezzotti G, Serafin A, Luzzi I, Mioni R, Milan M, Perin R: Occurrence and resistance to antibiotics of Campylobacter jejuni and Campylobacter coli in animals and meat in northeastern Italy. Int J Food Microbiol 2003, 82:281-287.

21. Mdegela RH, Laurence $K$, Jacob P, Nonga HE: Occurences of thermophilic Campylobacter in pigs slaughtered at Morogoro slaughter slab, Tanzania. Trop Anim Health Prod 2001, 143(1):83-87.

22. Abley MJ, Wittum TE, Moeller SJ, Zerby HN, Funk JA: Quantification of Campylobacter in swine before, during and after slaughter process. J Food Production 2012, 75(1):139-143.

23. von Altrock A, Hamedy A, Merle R, Waldmann KH: Campylobacter spp. -Prevalence on pig livers and antimicrobial susceptibility. Prev Vet Med 2012, 109(1-2):152-157. doi: 10.1016/j.prevetmed.2012.09.010.
24. Jonker A, Picard J: Antimicrobial susceptibility in thermophilic Campylobacter species isolated from pigs and chickens in South Africa. J South African VetAssoc 2010, 81:228-236.

25. Gallay A, Prouzet-Mauléon V, Kempf I, Lehours P, Labadi L, Camou C, Denis M, de Valk H, Desenclos JC, Megraud F: Campylobacter antimicrobial drug resistance among humans, broiler chickens, and pigs France. Emerg Infect Dis 2007, 13:259-601

26. Van Hees $B C$, Veldman-Ariesen $M$, de Jongh $B M$, Tersmette $M$, van Pelt $W$ : Regional and seasonal differences in incidence and antibiotic resistance of Campylobacter from a nationwide surveillance study in the Netherlands: an overview of 2000-2004. Clin Microbiol Infect 2007, 13:305-310.

27. Varela N, Friendship R, Dewey C: Prevalence of resistance to 11 antimicrobials among Campylobacter coli isolated from pigs on 80 grower-finisher farms in Ontario. Can J Vet Res 2007, 71:189-194.

28. Larkin C, van Donkersgoed C, Mahdi A, Johnson P, McNab B, Odumeru J: Antibiotic resistance of Campylobacter jejuni and Campylobacter coli isolated from hog, beef, and chicken carcass samples from provincially inspected abattoirs in Ontario. J Food Prot 2006, 69:22-26.

29. Aarestrup FM, Nielsen EM, Madsen $M$, Engberg J: Antimicrobial susceptibility patterns of thermophilic campylobacter spp. From humans, pigs, cattle, and broilers in Denmark. Antimicrob Agents Chemother 1997, 41:2244-2250

30. Payot S, Dridi S, Laroche M, Federighi M, Magras C: Prevalence and antimicrobial resistance of Campylobacter coli isolated from fattening pigs in France. Vet Microbiol 2004, 101:91-99.

31. Mattheus W, Botteldoorn N, Heylen K, Pochet B, Dierick K: Trend analysis of antimicrobial resistance in campylobacter jejuni and campylobacter coli isolates from Belgian pork and poultry meat products using surveillance data of 2004-2009. Foodborne Pathog Dis 2012, 9:5.

32. Sato K, Bartlet PC, Kaneene JN, Downs FP: Comparison of prevalence and antimicrobial susceptibilities of Campylobacter spp. isolates from organic and conventional dairy hers in Wisconsin. Appl Environ Microbiol 2004, 70:1442-1447.

33. Thakur S, Gebreyes WA: Prevalence and antimicrobial resistance of Campylobacter in antimicrobial-free and conventional pig production systems. J Food Prot 2005, 68:2402-2410.

34. Norma PV, Friendship R, Dewey C: Prevalence of resistance to 11 antimicrobials among Campylobacter coli isolated from pigs on 80 grower-finisher farms in Canada. Can J Vet Res 2007, 71:189-194.

35. Oosterom J, Dekker R, De Wilde GJA, van Kempen-de TF, Engels GB: Prevalence of Campylobacter jejuni and Salmonella during pig slaughtering. Vet Q 1985, 7:31-32.

36. Nesbakken T, Eckner $K$, ROtterud OJ: The effect of blast chilling on occurance of human pathogenic Yersinia enterocolitica compared to Campylobacter spp. and numbers of hygienic indicator on pig carcass. Int J Food Microbiol 2008, 123(1-2):130-133.

37. ICMSF: Micro-Organisms in Foods 6. Microbial Ecology of Food Commodities. International Commission on Microbiological Specifications for Foods (ICMSF). London: Blackie Academic and Professional; 1998.

doi:10.1186/1471-2180-14-85

Cite this article as: Ghimire et al:: Prevalence, antibiogram and risk factors of thermophilic campylobacter spp. in dressed porcine carcass of Chitwan, Nepal. BMC Microbiology 2014 14:85.

\section{Submit your next manuscript to BioMed Central and take full advantage of:}

- Convenient online submission

- Thorough peer review

- No space constraints or color figure charges

- Immediate publication on acceptance

- Inclusion in PubMed, CAS, Scopus and Google Scholar

- Research which is freely available for redistribution 